\title{
Gender, Grade and Personality Differences in Internet Addiction and Positive Psychological Health among Chinese College Students \\ Qian Dai*
}

Department of Centre for Psychological Health and Education, Sichuan University, China

\begin{abstract}
The purpose of this research is to investigate the prevalence of internet addiction and positive psychological health among Chinese college students and to explore the relationship of positive psychological health and internet addiction. A total number of 811 university students (the mean age: 19.70 years) who completed a on line survey that included the Internet Addiction Test (IAT) and PERMA scale. According to results, internet addiction was different between grade and personality and psychological health was different in gender and personality. Students with higher levels of internet addiction are more likely to be low in positive psychological health. The results indicated that positive psychological health was affected by Internet addiction negatively; and provided a better understanding on the positive psychological interventions in reduce internet addiction among Chinese college students.
\end{abstract}

Keywords: Positive psychological health; Internet addiction; College students

\section{Introduction}

Internet services as a technological advancement tool, which offers several direct benefits in our daily life. Internet delivers some practical purpose such as on-line shopping, business transaction, communication, social sharing and entertainment [1-3]. Despite those inherent advantages, many studies showed excessive internet use attribute negative effects to people's physical, social and psychological health, such as tiredness depression; loneness lower self-esteem [47]. Moreover, some studies found that excessive internet use affects students' educational performance, such as decrease in academic performance; wasting of time; problem in communication with peers [8-10].

\section{Internet addiction}

There are different terminologies in define excessive use of internet. The concept of internet addiction was first introduced by Young, and it appeared to be the most frequently used term in the literature $[11,12]$. Internet addiction has been considered as an impulse control disorder, which does not involve an intoxicant [1]. It is appeared to be a kind of technology addiction and a behavioral addiction similar to a gambling habit [9]. Internet addiction has been coined as "pathological Internet use (PIU)" and "problematic Internet use" [13,14]. Although there is still lack of a consensual definition of internet addiction, many scholars have agreed that internet addiction is a maladaptive pattern of internet use $[15,16]$. It does not only time-consuming, but also lead to clinically significant impairment, and negative, behavioral, psychological and physical consequences $[17,18]$

Increasing attention has focused on internet addiction as it has become a universal problem, particularly has negative influence to young people. Research showed adolescents is more easily to be influenced by internet addiction $[19,20]$. Internet addiction is very prevalent among secondary school and university students [21]. Identified $10.6 \%$ of Chinese college students are internet addicted. Noticeably, the research showed excessive or pathological use of internet is visible to different cultures [22,23]. Research with European adolescents identified poor sleeping problems and risk-behaviors were strongly associated with their internet addiction [24]. By using a national representative dataset, $\mathrm{Ha}$ and Hwang's study found that internet addiction was prevalent among Korean adolescents. After control for gender, internet addiction has showed negative correlation to adolescents' physical well-being and subjective happiness [25]. Based those research evidences, it is plausible to say that internet addiction is a problem that has been observed in both Eastern and Western culture and it is particularly cause psychological distress to adolescents.

\section{Positive psychological well-being}

Positive psychology in recent years has been one of the rapidly expanding subfields in psychology that has potential contributions to the field of internet addiction. Positive psychology seeks to explore factors and develop methods to help individuals find paths to thriving and flourishing; it is the study of the human strengths and virtues that make people feel good about lives. Based on its tenets, positive psychology has been utilized to the workings of positive experiences and positive personality traits that enable people to find lives of happiness, fulfillment and meaning and in turn to reach their full potential [2] Decades of research in the discipline have shown the value in studying people's positive psychological character that shape healthy well-being and demonstrated the effects of positive traits as buffers, helping people, for example, cope with stress in life and fix psychological disorders [26,27].

One of the prominent models in the field of positive psychology is PERMA (Positive emotions, Engagement, Relationships, Meaning and Accomplishment). PERMA was developed by the co-founder, Martin Seligman, of positive psychology as a conceptual model to help people flourish [2]. Positive emotions as the first aspect of the PERMA model are believed to be able to broaden one's awareness, stimulate one's innovative thoughts and develop one's skills for future actions [28]. Engagement refers to individuals who are absorbed by the activity and concentrate on the tasks without the awareness of the time

*Corresponding author: Qian Dai, Department of Center for Psychologica Health and Education, Sichuan University, China, Tel: +86 (0)28 85992256; E-mail: daiqian_1111@hotmail.com

Received November 23, 2016; Accepted December 13, 2016; Published December 20, 2016

Citation: Dai Q (2016) Gender, Grade and Personality Differences in Internet Addiction and Positive Psychological Health among Chinese College Students. Primary Health Care 6: 248. doi:10.4172/2167-1079.1000248

Copyright: (c) 2016 Dai Q. This is an open-access article distributed under the terms of the Creative Commons Attribution License, which permits unrestricted use, distribution, and reproduction in any medium, provided the original author and source are credited. 
[29,30]. Positive relationships emphasize the importance of individuals integrated themselves to society or community, been cared by important others and established one's social network [31]. Positive relationships are associated to decreased depressive symptoms and increased health outcomes [32]. Meaning refers to having a purpose and direction in life [2]. Although meaningful does not necessarily mean happy life, individuals who reported to have meaningful life were associated to wellbeing [33]. Accomplishment can be perceived as someone who is motived to achieve, to master and to competence in his best possible [2].

As the increasing research evidence has acknowledged that wellbeing can not only help to decrease stress and depression, it is also help individuals to become more productive, initiative and enable to build better relationship with others $[34,35]$. Therefore, the current study hypothesized that positive psychological health is negatively correlated to internet addiction. The people who are more addicted to internet may have lower grade of positive psychological health. In the present study, the researcher conducted an on-line survey to college-level students in China to explore their positive psychological health and internet addiction.

\section{There are four research questions formulated in the study}

1. Whether internet addiction is different between gender, grade and self-reported personality type? It is hypothesized that the level of internet addition will different between gender, grade and selfreported personality type. The extrovert students will feel less addicted to internet that introverts students.

2. Whether positive psychological health is different between gender, grade and self-reported personality type? It is hypothesized that positive psychological health is different in gender, grade and selfreported personality type. Students with extrovert personalities will score higher in positive psychological health.

3. Is there any relationship between internet addiction and positive psychological health? It is hypothesized that internet addiction is negatively correlated to positive psychological health.

4. Is there psychological health differ among different severity internet addicts? It is hypothesized that students who have better positive psychological health will have lower levels of internet addition.

\section{Materials and Methods}

\section{Participants}

There is a total number of 811 university students participated in the on line survey (Mean age $=19.70, \mathrm{SD}=1.40$ ). Of the participants, 406 (50.1\%) were freshmen, 254 (31.3\%) were second-year students, $111(13.7 \%)$ were third-year students and 40 (4.9\%) were fourth-year students. The participants were composed of $345(42.5 \%)$ male students and 466 (57.5\%) female students.

The investigator designed background information to investigate the questions on the time spending on internet, purpose of using internet, and self-reported personality. Average daily hours of Internet use were 5.75 hours for the whole sample. There were no significant gender differences in spending the time on internet (Male: $M=5.57$, $\mathrm{SD}=4.21$; Female: $\mathrm{M}=5.85, \mathrm{SD}=3.42$ ). Regarding to main purpose of using internet, free responses to the question have been content analyzed into four categories: on line gaming (38.6\%), communication tools (32.4\%), searching information (21.3\%), entertainment (27.5\%), assistant tool with studies (19.8\%). In terms of personality type, 111 (13.7\%) students classified themselves as introvert personality, 158
(19.5\%) of them were extrovert personality, 526 (64.9\%) of them were combined personality (both introvert and extrovert) and $16(2.0 \%)$ of them perceived their personality as others (including very hard to describe, very strange, I do not know).

\section{Measurements}

The internet addiction test (IAT): IAT test is developed from Internet Addiction Diagnostic Questionnaire (IADQ) [1,11]. It is composed of 20 items with 6 point scale, range from "rarely" coded 1 to "always' coded 5 and the other response option is "does not apply" coded as 0 [36,37]. The total score of IAT ranged from $0-100$, with higher scores reflecting a greater tendency toward internet addiction. In addition, IAT differentiate the extent of internet using by setting up cutoff scores: normal Internet users (score range 0-30); mild internet user (score range 31-49); moderate internet user (score range 50-79) and severe internet user (score range 80-100). IAT test was translated into Mandarin Chinese and back translated into English by two researchers from Psychology field who are blind to the purpose of the study. After translation of the questionnaire, internal coefficients of consistence of scale was tested, the Cronbach Alpha was calculated as 0.924.

Perma scale: Perma scale constructed by Seligman was used in measure psychological wellbeing [2]. This scale consisted of 23 items, and results in six different dimensions: positive emotion, engagement, meaning, positive relationships, accomplishment and over all wellbeing. It used a 10-point likert scale range from "not at all" (coded 0) to "all the time" (coded 10). Similar to IAT test, the translation and back translation procedure was applied to PERMA Scale. The Cronbach's alpha was 0.902 .

\section{Procedure}

Convenience sampling was the method used while recruiting the participants. The investigator sent the online questionnaire link to contacts in universities' student associations located at Beijing (northern China), Chongqing (Southwestern China), Chengdu (Southwestern China), Shanghai (Eastern China). The snowballing process was used to recruit participants. The instruction of completing the online questionnaire reminded all the participants that this questionnaire was anonymous, and all their answers were for the use of research only and would be confidential. Subjects were free to withdraw from the study at any stage.

\section{Results}

\section{Comparison of interest addiction by grade, gender and personality}

One way ANOVA was used to analysis the differences of internet addiction in different grade. The results showed the there was a significant differences of internet addiction across the different grade of university students: $\mathrm{F}(3,807)=5.82, \mathrm{p}<0.001$. Post hoc analysis showed the differences were between first year $(M=29.75, S D=17.22)$ and second year university students $(\mathrm{M}=24.56, \mathrm{SD}=15.47)$ and between second year $(M=24.56, S D=15.47)$ and fourth year university student $(M=31.38, S D=19.26)$. The study indicated that the first year and the fourth year University students were more addicted to internet than the second year of University students.

One way ANOVA was used to analysis the differences of personalities in internet addiction. The results revealed the significant differences of internet addiction in personality: $F(3,807)=3.19, p<0.05$. Post hoc analysis showed the significant differences were between 
adolescents' reported their personality as others $(\mathrm{M}=39.00, \mathrm{SD}=27.65)$ and all the other three types of personalities (introvert: $M=29,22$, $\mathrm{SD}=18.11$; extrovert: $\mathrm{M}=26.18, \mathrm{SD}=16.98$; combination: $\mathrm{M}=27.70$, $\mathrm{SD}=15.76)(\mathrm{p}<0.01)$. However, the scores regarding internet addiction did not differ between genders $(\mathrm{p}>0.05)$.

\section{Comparison of positive psychological health by grade, gender and personality}

One way ANOVA was used to analysis the differences of personality in psychological health. The results showed there was significant difference of personality on psychological health (Table 1). In positive emotion, individuals with extrovert personality have significantly higher level of positive emotions than people with introvert, combination and others personality $(\mathrm{p}<0.01)$. Individuals have combination personality has significantly higher positive emotions than people with introvert personality $(\mathrm{p}<0.01)$.

In engagement, extrovert personality types showed more engagement than people with introvert and other personality $(p<0.01)$. Combination personality showed significantly higher level of engagement than that of introvert and other personality type $(\mathrm{p}<0.05)$.

In relationship, people with extrovert personality scored significantly higher in relationship than people with introvert $(\mathrm{p}<0.001)$, combination $(\mathrm{p}<0.01)$ and others personality $(\mathrm{p}<0.05)$. Individuals with combination personality scored significantly higher in relationship than people with introvert personality $(\mathrm{p}<0.05)$.

In meaning of life, people with extrovert personality has scored significantly higher than people with introvert $(\mathrm{p}<0.001)$, combination $(p<0.01)$ and others personality people $(p<0.05)$. Individuals have combination personality has score significantly higher than people with introvert personality $(\mathrm{p}<0.001)$.

In accomplishment, people with extrovert personality scored higher in accomplishment than people with introvert $(\mathrm{p}<0.001)$ and combination personality $(\mathrm{p}<0.05)$. People with combination personality scored higher than introvert personality $(\mathrm{p}<0.001)$.

In overall wellbeing, people with extrovert personality scored higher than people with other three types of personality $(\mathrm{p}<0.01)$. People with combination personality scored higher than people in introvert personality $(\mathrm{p}<0.001)$.

In terms of examining gender differences in positive psychological health, T-test revealed female students showed more positive emotion, relationship, and overall wellbeing than male students: positive emotion, $\mathrm{t}=-2.39, \mathrm{df}=809, \mathrm{p}<0.05$, (Female: $\mathrm{M}=6.47, \mathrm{SD}=1.76$; Male: $\mathrm{M}=6.16, \mathrm{SD}=1.88$ ), relationships, $\mathrm{t}=-3.37 \mathrm{df}=809, \mathrm{p}<0.001$, (Female: $\mathrm{M}=6.49, \mathrm{SD}=1.71$; Male $=6.05, \mathrm{SD}=1.96)$ and overall wellbeing, $\mathrm{t}=-1.97$ $\mathrm{df}=809, \mathrm{p}<0.05$, (Female: $\mathrm{M}=6.16, \mathrm{SD}=1.46$; Male=5.95, $\mathrm{SD}=1.59$ ). However, no significant differences were found among grade in positive psychological health.

\section{Comparison of severity of internet addiction in positive psychological health}

According to cut off scores in IAT, scores in IAT have been divided into four groups (normal, mild, moderate and severe) depending on their severity of using internet [1]. One-way ANOVA was used to examine the different level of using internet in positive psychological health. Except engagement, there were significant differences of positive psychological health score in different level of internet addicts (Table 2). In positive emotion, there was no significant different of positive emotions between severe and moderate internet users. Except that, positive emotion score was decreasing with the severity of internet using was increased. Regarding to relationship, meaning and accomplishment and overall wellbeing, the differences were existed between normal internet user and other three levels of internet addicts $(\mathrm{p}<0.001)$.

\begin{tabular}{|c|c|c|c|c|c|}
\hline & & $\mathbf{N}$ & Mean & SD & Sig \\
\hline \multirow{4}{*}{ Positive emotion } & Introvert & 111 & 5.57 & 1.57 & \multirow{4}{*}{$F(3,807)=12.73, p<0.001$} \\
\hline & Extrovert & 158 & 6.87 & 1.96 & \\
\hline & Combination & 526 & 6.36 & 1.74 & \\
\hline & Others & 16 & 5.52 & 2.27 & \\
\hline \multirow{4}{*}{ Engagement } & Introvert & 111 & 5.43 & 1.63 & \multirow{4}{*}{$F(3,807)=4.14, p<0.01$} \\
\hline & Extrovert & 158 & 5.97 & 1.92 & \\
\hline & Combination & 526 & 5.86 & 1.58 & \\
\hline & Others & 16 & 4.90 & 2.24 & \\
\hline \multirow{4}{*}{ Relationships } & Introvert & 111 & 5.81 & 1.78 & \multirow{4}{*}{$F(3,807)=6.43, p<0.001$} \\
\hline & Extrovert & 158 & 6.73 & 1.99 & \\
\hline & Combination & 526 & 6.30 & 1.74 & \\
\hline & Others & 16 & 5.63 & 2.48 & \\
\hline \multirow{4}{*}{ Meaning } & Introvert & 111 & 5.33 & 1.92 & \multirow{4}{*}{$F(3,807)=7.67, p<0.001$} \\
\hline & Extrovert & 158 & 6.41 & 2.00 & \\
\hline & Combination & 526 & 5.96 & 1.84 & \\
\hline & Others & 16 & 5.33 & 2.17 & \\
\hline \multirow{4}{*}{ Accomplishment } & Introvert & 111 & 5.22 & 1.73 & \multirow{4}{*}{$F(3,807)=7.59, p<0.001$} \\
\hline & Extrovert & 158 & 6.20 & 1.86 & \\
\hline & Combination & 526 & 5.80 & 1.63 & \\
\hline & Others & 16 & 5.33 & 2.09 & \\
\hline \multirow{4}{*}{ Overall well-being } & Introvert & 111 & 5.50 & 1.37 & \multirow{4}{*}{$F(3,807)=10.72, p<0.001$} \\
\hline & Extrovert & 158 & 6.48 & 1.69 & \\
\hline & Combination & 526 & 6.09 & 1.43 & \\
\hline & Others & 16 & 5.36 & 2.07 & \\
\hline
\end{tabular}

Table 1: Scores of psychological well-being in different personality types (Number, Mean, SD, Sig). 


\begin{tabular}{|c|c|c|c|c|c|}
\hline & & $\mathbf{N}$ & Mean & Std. Deviation & Sig \\
\hline \multirow{4}{*}{ Positive emotion } & Normal & 499 & 6.60 & 1.87 & \multirow{4}{*}{$F(3,807)=13.80, p<0.001$} \\
\hline & Mild & 227 & 6.12 & 1.66 & \\
\hline & Moderate & 81 & 5.42 & 1.40 & \\
\hline & Severe & 4 & 4.25 & 2.28 & \\
\hline \multirow{4}{*}{ Engagement } & Normal & 499 & 5.87 & 1.75 & \multirow{4}{*}{$F(3,807)=1.44, p>0.05$} \\
\hline & Mild & 227 & 5.77 & 1.52 & \\
\hline & Moderate & 81 & 5.61 & 1.63 & \\
\hline & Severe & 4 & 4.50 & 2.89 & \\
\hline \multirow{4}{*}{ Relationships } & Normal & 499 & 6.55 & 1.92 & \multirow{4}{*}{$F(3,807)=9.82, p<0.001$} \\
\hline & Mild & 227 & 6.01 & 1.62 & \\
\hline & Moderate & 81 & 5.71 & 1.52 & \\
\hline & Severe & 4 & 4.25 & 2.32 & \\
\hline \multirow{4}{*}{ Meaning } & Normal & 499 & 6.27 & 2.015 & \multirow{4}{*}{$F(3,807)=13.59, p<0.00$} \\
\hline & Mild & 227 & 5.54 & 1.65 & \\
\hline & Moderate & 81 & 5.18 & 1.46 & \\
\hline & Severe & 4 & 5.00 & 1.19 & \\
\hline \multirow{4}{*}{ Accomplishment } & Normal & 499 & 6.08 & 1.81 & \multirow{4}{*}{$F(3,807)=15.10, p<0.00$} \\
\hline & Mild & 227 & 5.46 & 1.46 & \\
\hline & Moderate & 81 & 5.00 & 1.26 & \\
\hline & Severe & 4 & 4.25 & 2.60 & \\
\hline \multirow{4}{*}{ Overall well-being } & Normal & 499 & 6.31 & 1.60 & \multirow{4}{*}{$F(3,807)=13.72, p<0.001$} \\
\hline & Mild & 227 & 5.81 & 1.34 & \\
\hline & Moderate & 81 & 5.42 & 1.04 & \\
\hline & Severe & 4 & 4.39 & 2.11 & \\
\hline
\end{tabular}

Table 2: Scores of psychological well-being in different severity of internet addiction (Number, Mean, SD, Sig).

\section{Correlation between internet addiction and positive psychological health}

The correlation test was used to analysis the relationship between internet addiction and positive psychological health. The results showed there was a significant negative correlation between internet addiction and positive emotion $(\mathrm{r}=-0.228, \mathrm{~N}=811, \mathrm{p}<0.001)$; between internet addiction and relationships $(\mathrm{r}=-0.202, \mathrm{~N}=811, \mathrm{p}<0.001)$; between internet addiction and meaning $(\mathrm{r}=-0.259, \mathrm{~N}=811, \mathrm{p}<0.001)$; between internet addiction and accomplishment $(\mathrm{r}=-0.242, \mathrm{~N}=811$, $\mathrm{p}<0.001)$, between internet addiction and overall-wellbeing $(\mathrm{r}=-0.236$, $\mathrm{N}=811, \mathrm{p}<0.001)$. There was no significant correlation between internet addiction and engagement $(\mathrm{r}=-0.044, \mathrm{~N}=811, \mathrm{p}>0.05)$.

\section{Discussion}

The aim of this study was to investigate the internet addiction and psychological health among Chinese college students. The results showed significant grade differences of internet addiction among university students. First-year and fourth-year university students were more addicted to internet than the second-year of university students. The first year and the fourth year of university students were more prone to addicted to internet may due to they have more free time and less academic pressure than second year of University students. This finding was not completed agreed with the previous studies which showed senior grade students exhibited more internet addiction than those in junior classes due to the fact that senior grade students may use internet for academic activities. In the current study, the most senior and the most junior year of university students showed more addiction to internet than students in the middle year of the university.
In addition, personality showed significant influence in internet addition and positive psychological health. Individuals reported themselves to have "others" personality was more addicted to internet than those with three other personality types (introvert, extrovert and combination). This finding suggested that internet addiction were more sever in ones who have no clue of their personality looks like. However, people with extrovert, introvert and combination personality have no differ in internet addiction. This is consistent with the previous study which showed after controlled by age and gender, individual differences in personality were not significantly related to internet addition [38].

In terms of personality differences in positive psychological health, the current study showed individuals reported themselves as extrovert personalities showed more positive emotion, more engagement, better relationships, more meaning in life, better accomplishment and overall wellbeing than people with introvert and combinations personalities. Individuals with combination of both introvert and extrovert personalities have better psychological health than people with introvert personalities. This is in line with the previous study in which suggested personality dispositions such as extraversion, neuroticism, and selfesteem can markedly influence levels of subjective wellbeing [39].

Gender was not found differ in internet addition in the current study. It is in line with Beranuy et al's study that there were no gender differences in internet addition [40]. However, it is disagreed with other studies pointed male college students were more likely to addicted to internet than female students $[41,42]$. In terms of psychological health, female students scored higher in positive emotion, relationship and over all wellbeing than male students. This is consistent with previous studies that women in general are more willing to express and share 
positive emotions than men as well as more attuned to create and sustain meaningful social relationships [43].

'The study revealed normal internet user has better positive psychological health than mild, moderate and severe internet users. Individuals with more positive emotions related to less severity of internet addition. A large number of research evidences have suggested internet addiction hindering people's emotional problems, such as anxiety, depression, as well as social skills [1]. Within the framework of the body of research on internet addition and wellbeing, negative effect of internet addiction and subjective wellbeing, as illustrated by the present study [44].

The final research question examined the relationships between internet addiction and positive psychological health. Mainly, as hypothesized, internet addiction has negatively correlated with positive psychological health (positive emotion, relationships, meaning, accomplishment and overall-wellbeing) among college students. The finding supported previous study in which stated individual's subjective health was negatively related to internet addiction. In Diener's study, subjective well-being encompasses satisfaction with life, self-perceptions of well-being, satisfying relationships and positive emotions $[45,46]$. The present findings connoting that, internet addiction was negatively associated with psychological well-being is consistent with previous research. In return, it appears that if individuals can enhance their positive psychological health, they may decrease their internet addiction [47].

\section{Conclusion}

The study discussed the recent research in internet addiction and positive psychological health, gathered empirical data from college students through on line survey. The study found that internet addiction is different in grade and personalities, whereas positive psychological health was different in personalities and gender among Chinese college students. Although the internet provides advantageous and convenience in adolescent's life, the normal internet users showed much more positive psychological health than mild, moderate and severe internet users indicated that internet addiction function negatively to college students' health and wellbeing. The strong correlation was observed between internet addiction and psychological well-being, underlines the importance of enhance positive psychological interventions in higher education, treating or preventing the internet addiction in adolescents.

\section{References}

1. Young KS (1998) Caught in the net: How to recognize internet addiction and a winning strategy for recovery. John Wiley and Sons, New York.

2. Seligman MEP (2011) Learned optimism: How to change our mind and your life. Vintage: Knopf Doubleday Publishing Group.

3. Bradley K (2005) Internet lives: Social context and moral domain in adolescent development. New Directions for Youth Development 108: 57-76.

4. Akin A, Iskender M (2011) Internet addiction and depression, anxiety and stress. International Online Journal of Educational Sciences 3: 138-148.

5. Yen JY, Ko CH, Yen CF, Wu HY, Yang MJ (2007) The Comorbid psychiatric symptoms of internet addiction: attention deficit and hyperactivity disorder (ADHD), depression, social phobia and hostility. J Adolesc Health 41: 93-98.

6. Morahan-Martin J, Schumacher P (2003) Incidence and correlates of pathological internet use among college students. Comput Human Behav 16: 13-29.

7. Aydin B, San S.V (2011) 3rd world conference on educational sciences - 2011 internet addiction among adolescents: The role of self-esteem. Procedia Social and Behavioral Sciences 15: 3500-3505.
8. Aboujaoude E (2010) Problematic internet use: an overview. World Psychiatry 9: 85-90.

9. Griffiths M (2000) Does internet and computer "addiction" exist? Some case study evidence. Cyber Psychology \& Behavior 3: 211-218.

10. Gross EF, Juvonen J, Gable S.L (2002) Internet use and well-being in adolescence. J Soc Issues 58: 75-90.

11. Young KS (1996) Internet addiction: The emergence of a new clinical disorder Presented at the 104th annual meeting of the American psychological association, Toronto, Canada.

12. Lai CM, Mak KK, Watanabe H, Ang RP, Pang JS, et al. (2013) Psychometric properties of the internet addiction test in Chinese adolescents. J Pediatr Psychol 38: 794-807.

13. Young KS (2004) Internet addiction a new clinical phenomenon and its consequences. Am J Health Behav 48: 402-415.

14. Kaltiala-Heino R, Lintonen T, Rimpelä A (2004) Internet addiction? Potentially problematic use of the internet in a population of 12-18 year old adolescents. Addiction Research \& Theory 12: 89-96.

15. Spada MM (2014) An overview of problematic Internet use. Addict Behav 39 3-6.

16. Laconi S, Rodgers RF, Chabrol H (2014) The measurement of internet addiction: A critical review of existing scales and their psychometric properties. Comput Human Behav 41: 190-202.

17. Weinstein A, Lejoyeux M (2010) Internet addiction or excessive internet use. Am J Drug Alcohol Abuse, pp: 277-283.

18. Wallace BE, Masiak J (2011) A review of internet addiction with regards to assessment method design and the limited parameters examined. Current Problems of Psychiatry 12: 558-561.

19. Mossbarger B (2008) Is "Internet addiction" addressed in the classroom? A survey of psychology textbooks. Comput Human Behav 24:468-474.

20. Yen JY, Ko CH, Yen CF, Chen SH, Chung WL, et al. (2008) Psychiatric symptoms in adolescents with Internet addiction: comparison with substance use. Psychiatry Clin Neurosci 62: 9-16.

21. Lin SSJ, Tsai CC (2002) Sensation seeking and internet dependence of Taiwanese high school adolescents. Comput Human Behav 18: 411-426.

22. Wu HR, Zhu KJ (2004a) Path analysis on related factors causing internet addiction disorder in college students. Chinese Journal of Public Health 20 1363-1366.

23. Cao F, Su L (2007) Internet addiction among Chinese adolescents: Prevalence and psychological features. Child: Care, Health and Development 33: 275-281.

24. Durkee T, Carli V, Floderus B, Wasserman C, Sarchiapone M, et al. (2016) Pathological internet use and risk-behaviors among european adolescents. Int J Environ Res Public Health 13: 294.

25. Ha YM, Hwang WJ (2014) Gender differences in internet addiction associated with psychological health indicators among adolescents using a national webbased survey. Int J Ment Health Addict12: 660-669.

26. Masten AS, Coatsworth JD (1998) The development of competence in favorable and unfavorable environments: Lessons from research on successfu children. Am Psychol 53: 205.

27. Seligman MEP, Csikszentmihalyi M (2000) Special issue on happiness excellence and optimal human functioning. Am Psychol 55: 5-183.

28. Fredrickson BL (2001) The role of positive emotions in positive psychology: The broaden-and-build theory of positive emotions. Am Psychol 56: 218.

29. Csikszentmihalyi M (1990) Flow: The psychology of optimal experience. New York: Plenum.

30. Csikszentmihalyi M (1997) Finding flow. New York: Basic Books.

31. Khaw D, Kern M (2014) A cross-cultural comparison of the PERMA model of well-being. At Berkeley, p: 10.

32. Perissinotto CM, Cenzer IS, Covinsky KE (2012) Loneliness in older persons: A predictor of functional decline and death. Arch Intern Med 172: 1078-1084.

33. Baumeister RF, Vohs KD, Aaker JL, Garbinsky EN (2013) Some key differences between a happy life and a meaningful life. J Posit Psychol 8: 505-516. 
Citation: Dai Q (2016) Gender, Grade and Personality Differences in Internet Addiction and Positive Psychological Health among Chinese College Students. Primary Health Care 6: 248. doi:10.4172/2167-1079.1000248

34. Wood AM, Joseph S (2010) The absence of positive psychological (eudemonic) well-being as a risk factor for depression: A ten year cohort study. J Affect Disord 122: 213-217.

35. Achor S (2012) Positive intelligence. Harvard Business Review 90: 100-102.

36. Young KS, de Abreu (2010) Internet addiction: A handbook and guide to evaluation and treatment. John Wiley \& Sons.

37. Young KS, Rogers RC (2009) The relationship between depression and internet addiction. Cyber Psychology \& Behavior 1: 25-28.

38. Hills P, Argyle M (2003) Uses of the internet and their relationships with individual differences in personality. Comput Human Behav 19: 59-70.

39. Diener E, Oishi S, Lucas RE (2003) Personality, culture and subjective well-Being: Emotional and cognitive evaluations of life. Ann Rev Psychol 54:403-425.

40. Beranuy M, Oberst U, Carbonell X, Chamarro A (2009) Problematic internet and mobile phone use and clinical symptoms in college students: The role of emotional intelligence. Comput Human Behav 25:1182-1187.

41. Gnisci A, Perugini M, Pedone R, Di Conza A (2011) Construct validation of the use, abuse and dependence on the internet inventory. Comput Human Behav 27: 240-247.

42. Wu HR, Zhu KJ (2004b) Path analysis on related factors causing internet addiction disorder in college students. Chinese Journal of Public Health 20: 1363-1364.

43. Kashdan TB, Mishra A, Breen WE, Froh JJ (2009) Gender differences in gratitude: Examining appraisals, narratives, the willingness to express emotions and changes in psychological needs. J Pers 77: 691-730.

44. Akın A (2012) The relationships between internet addiction, subjective vitality and subjective happiness. Cyber Psychology \& Behavior 15: 404-410.

45. Diener E (2000) Subjective well-being: The science of happiness and a proposal for a national index. Am Psychol 55: 34-43.

46. Diener E, Seligman M.E.P (2002) Very happy people. Psychol Sci 13: 81-84.

47. Lyubomirsky S (2001) Why are some people happier than others? The role of cognitive and motivational processes in well-being. Am Psychol 56: 239-249. 